\title{
THEORETICAL AND METHODOLOGICAL ASPECTS OF INTEGRATION RATIONAL APPROACH TO BUSINESS PROCESS MANAGEMENT
}

\section{Olena Herasymenko ${ }^{1}$}

${ }^{1}$ PhD (Economics), doctoral student of management and economic security department, Bohdan Khmelnytsky National University of Cherkasy, Ukraine, e-mail: em_gerasimenko@ukr.net, ORCID: https://orcid.org/00000002-3144-0709

Citation:

Herasymenko, O. (2020). Theoretical and methodological aspects of integration rational approach to business process management. Economics, Finance and Management Review, (1), 71-79. https://doi.org/10.36690/2674-52082020-1-71-79

Received: January 27, 2020 Approved: March 20, 2020 Published: March 25, 2020

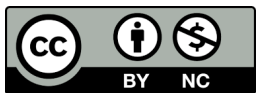

This article is an open access article distributed under the terms and conditions of the Creative Commons Attribution (CC BY-NC 4.0) license

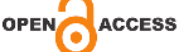

Abstract. The author explores the possibilities of using risk-oriented approach to business process management to ensure the economic security of enterprises. The purpose of this work is to study the theoretical and methodological aspects of risk management and, on their basis, to build a risk-oriented approach to management with subsequent integration into all business processes of the enterprise to ensure the economic security of the enterprise. During the research of problems of formation and integration of risk-oriented approach to management in the process of ensuring the economic security of the enterprise, and the method of synthesis was used - in the formation of individual elements of the structure of risk-oriented approach to manage in the process of ensuring the economic security of the enterprise; peer review method - to determine the priority of the identified risks of enterprises, to determine the weight of the selected methods and techniques during the identification, analysis and assessment of risks in the process of ensuring economic security. To provide a systematic approach to risk management an algorithm for processing risk using the recommendations ISO / IEC 27005 is proposed. A Risk acceptance scheme was created. Directions for improving EBITDA through risk management measures have been identified. The level of maturity of risk management systems is interrelated with the level of maturity of information technology. The necessity to increase the level of knowledge and competencies of specialists who provide economic security at enterprises is confirmed by studying the risk oriented approaches to business process management.

Keywords: risk-oriented approach, risk registry, risk card, residual risk, risk management, risk acceptability, maturity levels, stakeholders

JEL Classification: M20, M21

Formulas: 1; fig.: 3; tabl.: 1; bibl.: 7

Introduction. In the system of economic security, one of the central concepts is increasingly the concept of risk. Foreign scientists use this concept of risk management. For domestic companies, the problem of building effective mechanisms for ensuring economic security at the micro level has become increasingly urgent in recent years, especially in connection with the development and implementation of corporate governance principles. In order to solve this problem, it is advisable to study more deeply the experience in the field of enterprise risk management, which is an integral part of the system of economic security management in the practice of leading foreign companies.

It can be stated that the system of economic security management of the enterprise, especially in the financial sphere, has been developed quite well both in methodology and in practice and accordingly has developed tools for solving a certain range of problems. However, at the same time, there is no comprehensive risk management methodology that can be successfully used in the practice of non-financial sector entities, where the main risks are not material flows, but financial risks. At present, there is no scientific and 
conceptual approach to managing the economic security system in terms of risks, and accordingly there are no paradigms for solving management problems associated with certain risks. The top management of manufacturing enterprises has always had an urgent need to build the effectiveness of a risk-oriented economic security system. This is the right direction because not only financial risks but also all the variety of risks that threaten an enterprise need to be managed. Until that time, companies have used two tools in risk management insurance and regulatory standards (at the enterprise level - safety standards, regulations, instructions). Today, these measures are not enough: they are constantly changing, complicating business conditions, increasing reputation risk, increasing corporate responsibility of management for decision making. All of these are the consequences of an ill-considered risk management policy that threatens companies as a whole. In addition, if the security company chooses insurance protection, the cost of which is sufficiently significant, then the enterprise is limited only by the risk transfer policy.

Literature review. Among foreign scientists, in the field of scientific interests of which were the issues of effective management of economic entities using risk management, including various aspects of ensuring their economic security, such scientists as: Astakhov A., Girs K., D Walis, Jean-Paul Louis, Ketch K., Koutsky M., Rasmussen M., Nesterov S., Robert M. Lee, Moore A., Keynes J. Maynard. Knight K., Schwab K., Chlarden K. and others.

Paying tribute to the scientists whose research results have helped to establish the economic security of the enterprise as a science, it is worth noting that there is no risk-oriented approach to implementing the economic security of enterprises. In general, in the studies and publications of domestic scientists, the economic and managerial aspect of ensuring the economic security of enterprises is underdeveloped. Predominantly, the research focuses on the technical, informational, and power-related aspects that have traditionally been considered by enterprise security services.

Aims. The purpose of this work is to study the theoretical and methodological aspects of risk management and, on their basis, to build a riskoriented approach to management with subsequent integration into all business processes of the enterprise to ensure the economic security of the enterprise.

Methods. During the research of the problems of formation and integration of risk-oriented approach to management in the process of ensuring the economic security of the enterprise, a method of synthesis was used - in the formation of individual elements of the structure of risk-oriented approach to management in the process of ensuring the economic security of the enterprise; peer review method - to determine the priority of the identified risks of enterprises, to determine the weight of the selected methods and techniques during the identification, analysis and assessment of risks in the process of ensuring economic security.

Results. To ensure the economic security of the enterprise risk-oriented approach to management, it is proposed to use a modern risk management tool, 
which is formed on the basis of a set of methodological and technical techniques, methods and principles in their close relationship, which meet the needs of the modern enterprise.

One of the methods proposed to apply the risk-oriented management method to ensure the economic security of the enterprise is to use a risk register and a risk map. The registry identifies the risk factors that may arise, the possible risk events and the consequences of their occurrence that the company may face, information risk management measures. As a rule, the risk management system is developed in a sufficiently detailed manner for all types of risks, including causal relationships between them. Next, each risk listed in the registry must be ranked based on the likelihood of a risk event and possible loss. This ranking serves as the basis for creating an information risk map. In general, the risk map is a powerful tool for analyzing and prioritizing them. The risk map, including information risks, plays an important role in assessing the strategic actions of the company, in forecasting and planning its activities. The process of creating it is complex and often requires the involvement of external consultants.

Discussion. To provide a systematic approach to risk management, a set of documents is required such as [1]: 1. Risk management policy; 2. Corporate standard of risk management; 3. Risk management methodologies (regulations, report formats); 4. Risk register; 5. Regulations on the risk management unit; 6 . Job descriptions including risk management functions; 7. Risk map.

The risk register is one of the most important documents managed by the risk management unit or risk manager. Therefore, it is necessary to find out what this document is. The risk register is a document containing the results of qualitative and quantitative risk analysis, risk response planning. The Risk Registry thoroughly considers all known risks and includes a description, category, cause, likelihood, impact on goals, anticipated response, owners and current status. The risk register is an element of the company's risk management plan.

Risk identification and having a real, objective view of the risks involved are one of the foundations of effective risk management that contributes to the achievement of the company's goals. The result of the risk identification shall be a risk register containing a list of identified risks; potential reactions to them by the enterprise; the main factors that determine the identified risks; and additional categories entered during the identification process. Risk identification provides a tool for recording and reporting potential adverse events that may adversely affect the achievement of the goals and objectives set by the company and each employee, as well as determining the direction and need to improve the risk management process. Risk identification helps to increase the level of confidence in achieving the tasks by obtaining a review of the risks and their main characteristics, determining the relationship of risks with each other, ranking the level of company risks, raising awareness about risks and methods of managing them, as well as focusing on the most critical risks . 
Risks that have been assessed as catastrophic are considered urgent. Deciding on a particular method of treatment as the most accepted means balancing the costs of implementing each activity with the benefits. Thus, we formulate the formula: the expediency of the risk management method is the cost of risk management $=$ the benefits received from risk management.

Once the risk assessment has been carried out, one or more appropriate means of changing the likelihood and / or impact of the risks should be selected and agreed upon during the risk management and implemented. We then go through a cyclical process of reassessing a new level of risk in order to determine its acceptability as compared to a previous risk level result. It should also be noted that there are two ways to handle risk: the first is to reduce the risk, that is, to reduce the level of potential loss from its realization, and the second is to reduce the likelihood of risk.

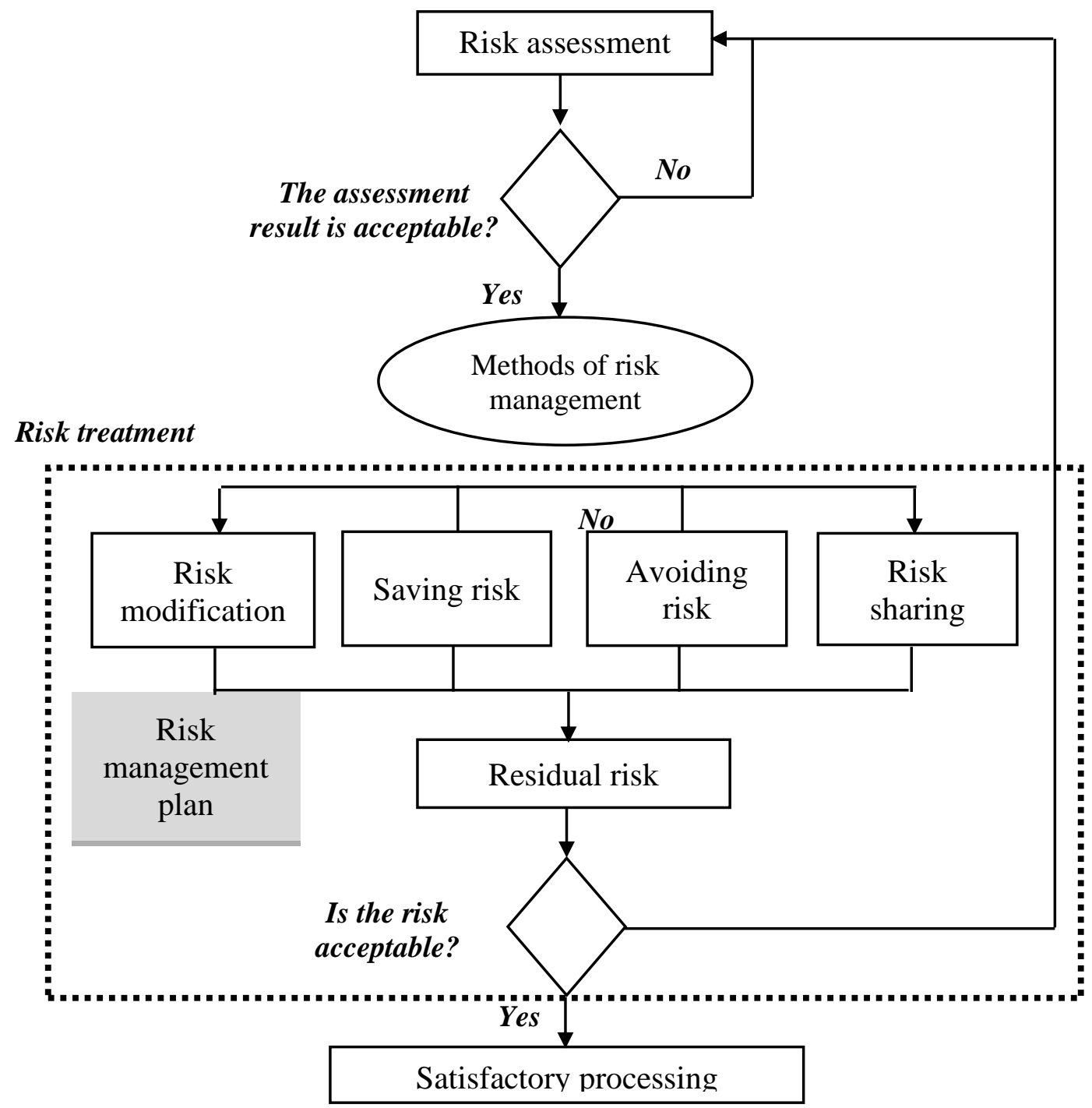

Figure 1. Algorithm for processing risk using recommendations ISO/IEC 27005

Source: developed by author [2] 
Marked on fig. 1 the four methods of risk management are not mutually exclusive, some of them may be effective for more than one risk.

Risk management methods may include one or more actions:

- avoidance of risk by deciding not to start or continue activities that give rise to risk;

- accepting or increasing the risk in order to take advantage of the opportunities;

- removal of the source of risk;

- change in probability;

- change of consequences;

- risk sharing (diversification);

- risk retention based on sound decision.

According to the algorithm for processing risk using the recommendations of ISO / IEC 27005 [2] and ISO 31000 [3], it is necessary that the risk assessment method allows to manage the risk in the following ways:

1. Risk modification: the level of risk should be managed through the introduction, exclusion or modification of control measures so that residual risk could be overestimated as acceptable. Appropriate and sound control measures must be selected to meet the requirements established in the risk assessment and management. The selection should take into account the risk criteria, regulatory, legislative and contractual requirements. The costs and timing of the control measures or the technical, environmental and cultural aspects should also be considered when making the choice.

2. Contingency Risk: There may be specific risks for which the entity cannot establish clear control measures or the costs of these control measures will outweigh the potential losses from the materialization of the risks. In this case, the enterprise may accept the consequences of the risk, if it is realized. The enterprise documents this decision.

3. Risk avoidance: if the identified risks are found to be too high or the costs of processing the risk outweigh the benefits, then a decision can be made to eliminate the risk completely by eliminating it from the intended type or entity, or by modifying the conditions under which the activity is carried out.

4. Risk Sharing: Risk Sharing involves the decision to share identified risks with external stakeholders. Risk sharing can create new risks or change already identified risks, so there is a need for additional risk management.

After the risk has been processed, there may be residual risk, which we define as the risk remaining after the implementation of the treatment measures, should be documented and remain subject to monitoring, analysis and, if necessary, further processing. This risk may involve another, not identified risk. It should be noted that risk should be identified and assessed in accordance with management requirements and at a satisfactory level for management. We define the residual risk as: 
When a risk management plan is implemented, there are always residual risks. After the risk has been processed, the magnitude of the risk reduction must be estimated, calculated and documented. It can be difficult to assess residual risk, but it must be brought into line with the enterprise's risk acceptance criteria. If the residual risk remains unacceptable after the implementation of the control measures, make a decision on how to handle it.

The next step after risk management is the risk acceptance process. Risktaking is a function that differs across industries, businesses and departments, such as operating activities. Acceptable risk is the risk that an enterprise may accept in the face of current social and organizational values (Fig. 2).

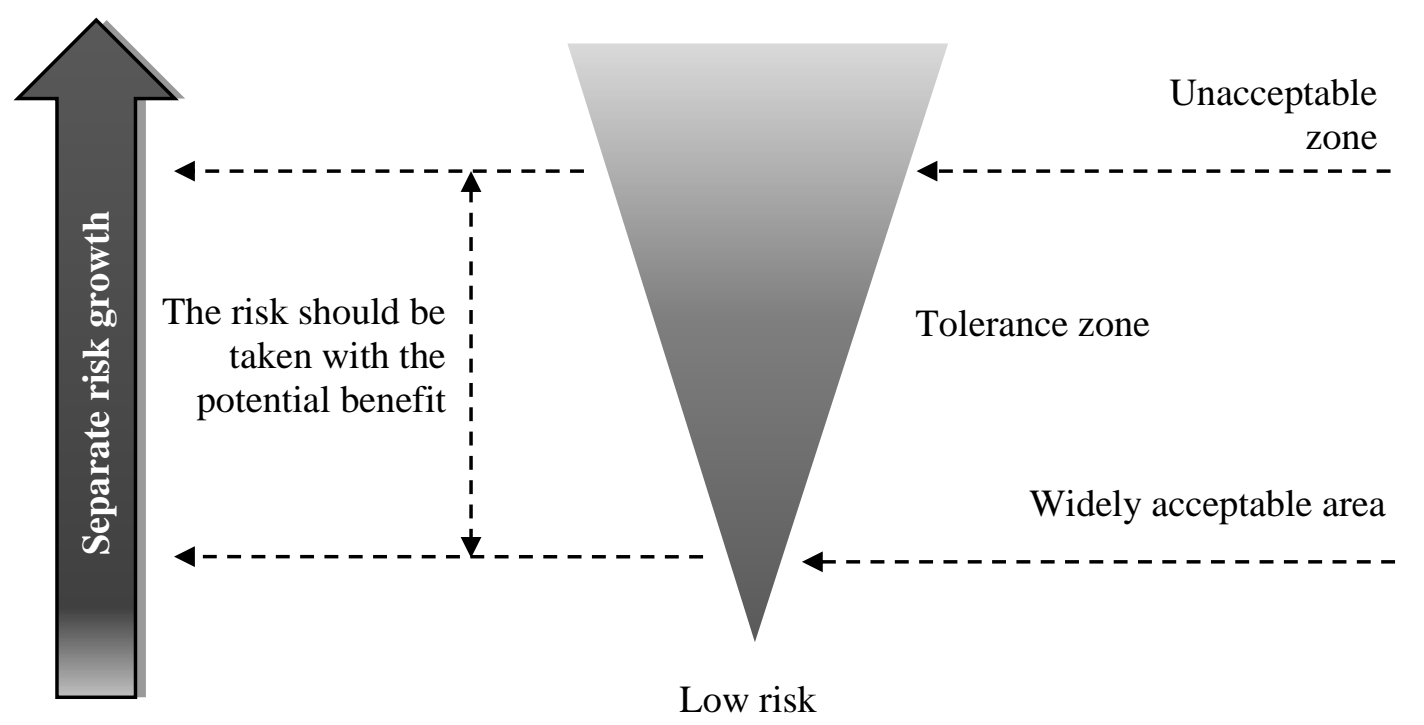

Source: developed by author

\section{Figure 2. Risk acceptance scheme}

An unacceptable zone is an area where the risk is too high and risk mitigation measures must be taken to take it. ALARP Zone (Risk Tolerance Zone) - The risk in the area is below the level of ineligibility, but it may remain unacceptable if no risk mitigation measures are taken. Widely Acceptable Zone An area in which the risk is acceptable, there is no need for additional risk management measures. Risk acceptance criteria are the criteria used as a basis for making risk acceptance decisions.

The ALARP method is based on an assessment of the cost of risk and the cost of mitigation. The principle of ALARP is that the risk should be kept to some low level. For this assessment, the ALARP principle relies on a global risk analysis system as described in European EN 50126 [4] and international CEI 61508 [5]. This approach implies the greatest possible reduction in the risk that is achieved by virtually limited resources available. That is, only those measures that are considered reasonable and affordable from a practical point of view are taken. The implementation of these measures should not require unreasonably high material or labor costs. 
It is proposed to improve the overall economic and economic performance of the enterprise in the three main areas, which are interacting. Some companies have the opportunity to pay greater attention to risk reduction throughout the enterprise, others to improve efficiency by optimizing the costs of control measures, and third - to improve financial results both by reducing the level of risk and by reducing costs (Fig. 3).

\begin{tabular}{|c|l|}
\hline \multicolumn{1}{|c|}{ Risk } \\
reduction
\end{tabular}$\quad \begin{aligned} & \text { In the worst-case scenario, the rate of increase in risk can far outstrip the } \\
& \text { response. An entity must have the ability to quickly identify, manage, and } \\
& \text { mitigate the major risks of a risk management system that involves: } \\
& \text { - identification and understanding of the most significant risks; } \\
& \text { - differentiated investments in managing the most significant risks for the } \\
& \text { enterprise; } \\
& \text { - effective risk assessment within business, creation of a system of reporting and } \\
& \text { personalized responsibility for risk management; } \\
& \text { - confirmation to investors, analysts and regulatory organizations (all } \\
& \text { stakeholders) of the effectiveness of the risk management system. }\end{aligned}$

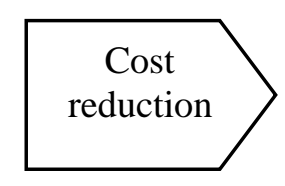

In an unstable economic environment, maintaining our own business depends largely on the ability to find opportunities to reduce costs across all areas of activity. Cost-cutting opportunities can come from:

- introduction of a new operational risk management model that will significantly improve the cost structure;

- reduction of costs for internal control due to the improvement of automated control procedures;

- optimization or elimination of duplication of functions in the field of risk management;

- increasing the efficiency of processes through the implementation of automated centers, business processes and continuous monitoring

Many businesses want risk management and internal controls to help improve business performance. The possibilities in this field are:

- increasing the return on investment in risk management;

- Acceptance of tolerable risks and allocation of responsibility for them among the designated units for competitive advantage;

- improving the internal control system in key business processes;

- use of analytical data to optimize the risk portfolio and improve the decision-making process;

- use of funds saved through risk management to finance strategic corporate initiatives.

\section{Figure 3. Directions for improving EBITDA through risk management measures}

Source: developed by author

The criteria for an ideal risk management system depend on many factors. First of all, it is important to consider who assesses what its goals are, what the risk management professionals are guided by. For example, a number of domestic banks are guided only by Basel II requirements, not by shareholders' opinion, but only by supervisory authorities. 
Each of the international standards of risk management requires continuous monitoring and control of risks, which depends on the level of management of information technology. Information technology in risk management processes, on the one hand, is a management tool and, on the other, a source of operational risk. The level of maturity of risk management systems is interrelated with the level of maturity of information technology.

Table 1. Levels of maturity of the risk management system

\begin{tabular}{|c|l|l|}
\hline $\begin{array}{c}\text { The level of } \\
\text { maturity }\end{array}$ & \multicolumn{1}{|c|}{ Level name } & \multicolumn{1}{|c|}{ Status of the risk management process } \\
\hline 0 & zero & are not used \\
\hline 1 & educational & $\begin{array}{l}\text { specialized and unorganized, beyond the general approach } \\
\text { repeated regularly and not an element of corporate } \\
\text { knowledge }\end{array}$ \\
\hline 2 & repetitive & $\begin{array}{l}\text { documented and interconnected, monitoring and control } \\
\text { rests with the contractors }\end{array}$ \\
\hline 3 & determined & $\begin{array}{l}\text { controlled, verified, measured, but reflecting the practice } \\
\text { of that particular entity only }\end{array}$ \\
\hline 5 & controlled & $\begin{array}{l}\text { are in line with best practice in the world and are } \\
\text { automated }\end{array}$ \\
\hline
\end{tabular}

Source: developed by author

Due to the wide application of the principles, the risk of management significantly increases the effectiveness of the key approach in system management, which is based on the closed management cycle of SchuhartDeming P-D-C-A (plan - execute - check - actions).

The application of this approach has become a classic and is present in all systems of management without exception. A major factor in this increase in the effectiveness of the classic P-D-C-A management cycle is the preliminary analysis and consideration of the most important threats and opportunities that are fulfilled within the management risk methodology applied to all stages of the organization's activities. In view of this fact, in all three standards, much more emphasis is placed on the next generation management systems to continually improve them and look for opportunities for such improvements.

The profession of risk-manager requires not only mastering economic, mathematical engineering methods, but also such general theoretical knowledge in management, probability theory, social psychology, economic analysis and audit, marketing, law, fundamentals of insurance and many more specific skills without knowledge, business, etc. It should be noted that a risk management professional must have global, associative, imaginative thinking, constantly develop experience and be able to use intuition.

The market for qualified specialists with experience in risk management in companies in the real sector of the economy is currently quite limited. The risk management company has the ability to do this with low-budget methods: to hire a qualified and experienced risk manager, giving him the opportunity to select a team. This method is quite effective, low-budget, but it is almost 
impossible for the Ukrainian labor market due to the very small number of specialists in this field. Due to the fact that finding a qualified risk manager for domestic companies is almost impossible today, the majority should assign to this position inexperienced employees with insufficient qualification. Yes, we expect that the experience will be gained in the process of implementing the corporate risk management system.

Conclusion. As a whole, it can be concluded that when successful companies seek to manage individual risks, future success will be attributable to those who take risk management to the next level. That is, those who implement the risk management method of the entire enterprise, covering the company as a whole. With complete and systematic information about the key business risks of their company, risk managers will be able to develop risk management plans and programs using coordinated, comprehensive and sophisticated methods. Effective risk management for the entire company is an indispensable element of its management in the 21 st century. When successful companies attempt to manage individual identified risks, future success will be attributed to those who are taking risk management to the next level, that is, those who take a risk-based management approach to ensure the economic security of the entire company.

\section{References:}

1. Herasymenko, O. (2013). Features of building a risk register based on identified events. Formation of market relations in Ukraine, 2, 102-107.

2. ISO/IEC 27005:2018 Information technology - Security techniques (2018). Information security risk management. Retrieved from https://www.iso.org/standard /75281.html?browse=tc.

3. ISO 31000:2018 Risk management - Guidelines (2018). Retrieved from https://www.iso.org/standard/65694.html

4. Committee on Technical Cooperation in the Development of the Rail Transport System / 11th July 2016 Reliability, Availability, Maintainability, (2016). Safety (RAMS) and Life Cycle Costs (LCC). Retrieved from http://www.otp.go.th /uploads/tiny_uploads/Public/2560/04-April/10-25590915EuropeRailStandard.pdf

5. CEI 61508-2:2010, Sécurité fonctionnelle des systèmes électriques /électroniques /électroniques programmables relatifs à la sécurité - Partie 2. (2010). Exigences concernan. Retrieved from https://webstore.iec.ch/preview/info_iec61508-1\%7Bed2.0\%7Db.pdf

6. Jean Paul Louisot, Christopher Ketcha (2014). ERM Enterprise Risk Management: Issues and Cases.

7. Michael Rasmussen (2010). Enterprise Risk Management Policy Structure. Retrieved from https://us1.campaign-archive. $c 0 m / ? \mathrm{u}=3 \mathrm{c} 21 \mathrm{fc} 3 \mathrm{e} 3 \mathrm{a}$ 4511ae9cb40a86b\&id=340e80ff3a 